\title{
Investigations on the relationship between perfectionism and psychological needs with the perception of body image in cosmetic surgery applicants
}

\author{
Soodabeh Yavari ${ }^{* *}$ and Asghar Jafari ${ }^{2}$ \\ ${ }^{\prime} M A$ Student of Counseling and Guidance, Faculty of Human Science, Abhar Branch, Islamic Azad \\ University, Abhar, Iran \\ ${ }^{2} P h D$, Faculty Member of Shahid Beheshti University, Tehran, Iran
}

\begin{abstract}
Physical appearance is an important part of the body image because it is the first source of information which others use it for social interactions with that individual. Every year tens of thousands are doing cosmetic surgery in order to eliminate dissatisfaction with their appearance and sometimes to increase self-esteem. The aim of this research was to investigate the relationship between perfectionism and psychological needs with the perception of body image in cosmetic (plastic) surgery applicants. Research population consists of all the men and women who were applicants for cosmetic surgery and had recourse to beauty clinic of Imam Khomeini hospital, Tehran, Iran. 200 individual samples were selected by availability sampling method. The method of this paper was descriptive-analytical and data collection is done using questionnaire. data were analyzed using SPSS. Results showed that there was a relationship between perfectionism and psychological needs with the perception of body image of cosmetic surgery applicants. Psychological and perfectionism needs and also the perception of body image of women are different from men's. In addition, the negative characteristics of perfectionism have a larger share in cosmetic surgery applicants' prediction of body image perception.
\end{abstract}

KEY WORDS: PSYCHOLOGICAL NEEDS, PERFECTIONISM, THE PERCEPTION OF BODY IMAGE

\section{ARTICLE INFORMATION :}

*Corresponding Author: sodabehyavari95@gmail.com Received $1^{\text {st }}$ June, 2017

Accepted after revision $25^{\text {th }}$ Sep, 2017

BBRC Print ISSN: 0974-6455

Online ISSN: 2321-4007 CODEN: USA BBRCBA

Thomson Reuters ISI ESC and Crossref Indexed Journal

NAAS Journal Score 2017: 4.31 Cosmos IF: 4.006

- A Society of Science and Nature Publication, 2017. All rights reserved.

Online Contents Available at: http//www.bbrc.in/

DOI: $10.21786 / \mathrm{bbrc} / 10.3 / 24$ 


\section{INTRODUCTION}

Physical appearance is an important part of the body image because it is the first source of information which others use it for social interactions with that individual. There is no official statistics on cosmetic surgery in Iran. According to unofficial statistics, every year, more than 36 thousands of Iranians do facial cosmetic surgery. Among the performed cosmetic surgeries in Iran, rhinoplasty is in the first place. According to unofficial statistics, from the numerical aspect of rhinoplasty, Iran is the first in the world. After Iran, countries such as America, England, and partly France are in the next ranks. Approximate statistics were only unofficial sources of cosmetic surgery. Those people, who desire to do these types of surgery but fear, should be added to this statistics. The concept of an individual's perception of their body is an important part of their self-concept. The body is the most visible part of ego and consciousness. Body image is person's internal visualization of external appearance which includes representation of physical, cognitive and attitudinal dimensions. The main dimensions of this attitude consist of components like evaluation and individual investment in dealing with schemes of appearance and emotion which reveal the importance of internalized appearance, (Sarwer, 2003, Cash, 2004, Borzekowski, 2005, Balali, 2010, Weiss, 2013, Nerini, 2014).

In the twentieth century, especially in recent decades, new concepts of beauty have emerged and beauty is defined as a collection of components such as fitness, makeup, clothes, attractiveness, and integrity. The combination of beauty and industrial and also medical achievements has caused that now, beauty is not a natural and biological characteristic anymore and it is an adventitious trait. Nowadays, cosmetic surgery is as one of the most common surgical procedure on a global level that the use of which is growing. The main purpose of cosmetic surgery is improving the appearance of the person who has the abnormal appearance. When people find out their physical properties are not in accordance with those norms, may be offended and consider the surgery as the final solution. Now, cosmetic surgery becomes an agent charming and luxury-oriented means to different people, and this has led to the establishment of people's unrealistic expectations and distortion of the facts about its true nature, (Hilhorst, 2002, Pearl, 2003, Hwang, 2004 Wolf, 2013).

These days, cosmetic surgery is taken into consideration for creating beauty and desired image, so the image of beauty as God's natural creation is drawn to adventitious and clinical beauty. With the increasing demand for plastic surgery, several studies of this field have introduced some effective factors on the desire to these types of surgery. These factors are dissatisfaction with body image, low attractiveness, psychological factors, body dysmorphic disorder, precedent of previous cosmetic surgery, social and interpersonal factors such as annoying appearance from the perspective of others, surgical precedent of family and friends, cultural factors, the impact of mass media advertising on TV, satellite, magazines, movie stars, stress pressure, medical System and beauty industries. At the end of the twentieth century, a major concern about body image was clearly felt, (Garrusi, 2013).

This concern has mainly surrounded women. Women whose body image has much importance for them, discontent and dissatisfaction of appearance is associated with their dissatisfaction of themselves and in general, with their life. Orientation about beauty is in all social situations. There is an irrational but firm belief that attractive people possess the other ideal characteristics such as intelligence, adequacy, social skills, confidence and even much moral values. Of course not surprising that physical attractiveness is very important; however, this as well as concerns about physical appearance is not limited to this century and at any time and historical period has been important and some criteria are determined for beauty and ugliness. Efforts of individuals across the life is attempting to what look like to show themselves in the best possible way. Physical appearance affect on others, even if it be accepted that these effects can be changed after the formation of communication (Rumsey, 2004).

Benfield and McCabe declared that body image has three dimensions: perceptual-evaluation, emotional and behavioral dimension. Perceptual-evaluation dimension refers to individuals' measurement and evaluation of their body. Feelings and emotions which individual experiences from her body lies in emotional dimension; and behavioral dimension focuses on the effect of persons' thoughts and emotions about their body on their behavior (Banfield, 2002).

Body image is consisting of two aspects: perceptual aspect (individual's evaluation of her body sizes) and emotional-cognitive aspect (person's attitude toward her limbs). According to available findings, the assumption is that when persons know their body lower than ideal criteria, may encounter with inappropriate feelings and attitudes about themselves like low self-esteem or depression (Pesa, 2000) and in some cases even causes a dropout. Cash introduced evaluation, emotion, and investment as three main dimensions of body image dimensions (Cash, 2004).

Socio-cultural theory as a prominent theory in the field of body image, and by raising the social and cultural variables on body image disorders, has received much empirical and research support. Of course, most 
of the studies have focused on women's social and psychological variables. This focus probably is due to the high prevalence of body dissatisfaction and body image disorders in women and young girls. The investigation found that the incidence of physical ideal for women is associated with their increasing body dissatisfaction (Hargreaves, 2006). Studies show that awareness and internalization of women's ideal are predictors of body dissatisfaction, body image, and a decrease of selfesteem. Cosmetic surgery includes carrying out all cosmetic surgery, including nose, eyelids, eyebrows, cheeks, forehead, neck and body beauty which may change (such as removing fat) or improve (e.g. dentures). Generally, cosmetic surgery refers to surgeries without the special medical necessity that is done solely for cosmetic purposes (Tavassoli, 2012).

Surgical breast implants in the United States is eight times since 1992. Also in 2001, 1.6 million people have been surgery Botox injections therein. This rise of statistics is also seen among the male population. In 2002, the number of men who use Botox injection for less showing their age has increased $88 \%$ and men who have undergone rhinoplasty surgery has increased 47\% (Ibid). For years, the negative image of the body has known as one of the reasons for resorting to plastic surgery. But few types of research have studied body image after surgery longitudinally. Sarwar and his colleagues in 2002 evaluated body image of patients before and after of cosmetic surgery (Heyes, 2016). A significant decrease of patients' dissatisfaction of operated limb than before the cosmetic surgery was reported. They also suffer less embarrassment in front of others' attention to that specific limb or talking about it. But there was no change in studied women's general body image. These results represented that people who undergo cosmetic surgery are rarely significant changes in their general discontent. Therefore, cosmetic surgery is a therapeutic plan for people who are dissatisfied with just one part of their body and face (Sarwer, 2003).

Many factors can contribute to the negative image of the body, including physiological factors (such as body mass index), psychological factors (like perfectionism, low self-esteem) and socio-cultural factors (such as family, peers, and media). In the contexts of perfectionism, both one-dimensional and multi-dimensional approach to perfectionism can be seen (McGee, 2005). Person-centered divisions of perfectionism are normal neurotic, satisfying- dissatisfying, and negative or positive perfectionism (Stoeber, 2007; Besharat, 2007). In the framework of person-centered approach, in addition to neurotic, abnormal and damaging roles of perfectionism which are more known, its normal and desirable and also positive effects are confirmed and clarified (Slade, 1998). According to this division, a normal perfectionist enjoys effort and competition for superiority and perfection and at the same time accept personal limits, although neurotic perfectionist due to unrealistic expectations, do not be satisfied with her performance (McGee, 2005).

Positive perfectionism: positive perfectionism (strive for positive progress) is to Try to achieve high personal standards without self-criticism. This aspect is not related to negative characteristics such as anxiety; positive perfectionism mainly focuses on expectations regarding progress, competition, capability, the excitement of a work and satisfaction. On the other hand, positive perfectionism is achieved by attaining positive and motivation to access a certain goal so that it has promising results (Haas, 2008). Despite the negative perfectionists (neuroticism), positive perfectionists (normal) at the same time that impose high personal standards for themselves, they can accept personal and environmental limitations and know their success, even if they do not meet their personal standards exactly. This group of perfectionists in an effort to succeed and achieving the goals, in terms of the ability to accept personal limitations and environmental barriers, can experience a sense of satisfaction more (Besharat, 2007).

Negative perfectionism: negative perfectionism dimension contains that form of perfectionism which explains perfectionism concerns such as too much attention to mistakes, doubts about negative actions and reactions. This dimension is associated with anxiety (Stoeber, 2007). Negative perfectionism is focused on emotions like not meeting expectations of the individual about herself and others, condemning, feeling guilty, shame and defeating (Haas, 2008). In addition, these persons strictly avoid failure and are vulnerable to criticism of others. This group of perfectionists treats the various spheres of social activity and relations as threatening, procrustean and not supportive (Besharat, 2007). The major difference between abnormal and dysfunctional perfectionism and positive and normal perfectionism is that in the first group despite conflicting evidence, perfectionist tendencies are continued (Figure 1).

The concept of basic psychological needs is completely different with the theory of personal efforts and wishes. Although people know the motivations as a provision of basic needs, but it is clear that there are many incentives that do not comply with the standards of welfare; in fact, it may be harmful. In the other words, may some incentives mislead the people about what can resolve their requirements and it means misleading their deviation of welfare? Even when people can satisfy their motivations, again the motivation can be harmful to the welfare if it barricades satisfying the needs of autonomy and communication (Ryan, 2000; Sheldon, 2001). Unfortunately, from the past till now there is little consensus about the criteria of psychological needs, where they 


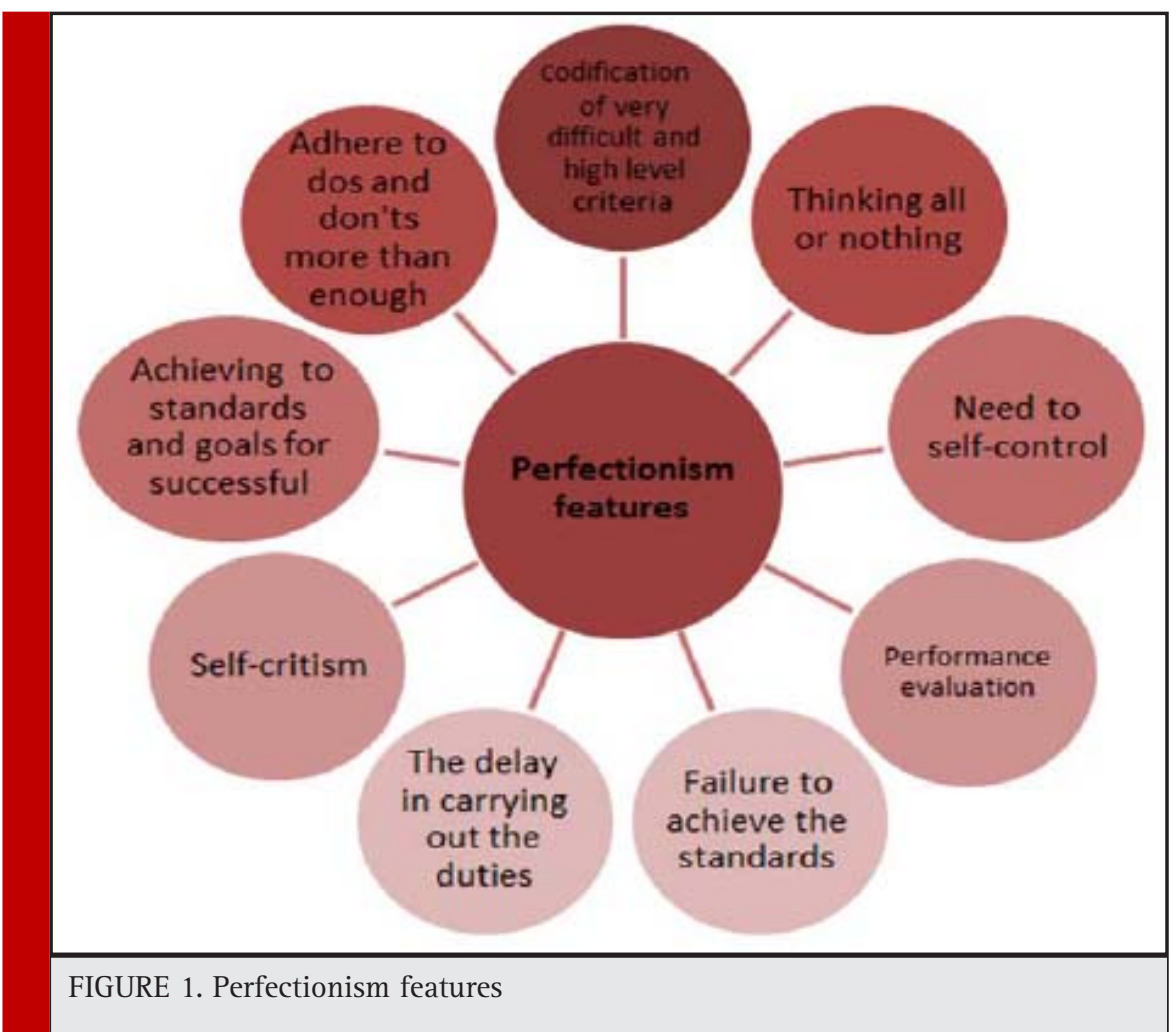

originated, whether thy are result of learning in childhood or cultural differences, whether they are inherent and universal and have been established by evolution in man; These are questions that need to be asked about (Sheldon, 2001). In this part, the importance of three psychological needs namely autonomy, competence, and relatedness are investigated. When people find themselves in an environment that helps them to develop their psychological needs and also fosters them, positive emotions, optimal experience, and healthy growth are its consequences. Psychological needs are important for the study of motivated behavior. The energy of psychological needs is pioneering. Psychological requirements induce a desire to seek the environment that is expected to bring up our needs (Azin, 2014).

Autonomy (independency): independency means person's need to electoral right and self-initiate for duties. For example, when people from the satisfaction and enthusiasm, spend their time and energy to study in order to feel autonomy (Ryan, 2000). Need to autonomy is a need to self-following and having the electoral right at the beginning maintenance and tuning the activities. Autonomy will happen when people feel the responsibility for their behavior, and confident in their choices and also the ability of eligible performance, (Sheldon, 2001). Autonomy means feeling volition, having authority of doing things, innate tendency for self-organized behavioral experience (Sheldon, 2001). Autonomy is related to freedom and experience of solidarity in personal behaviors.

Competence (adequacy): all people try and want to be competent. All want to have fruitful interaction with their environment and this interest is expanded to all aspects of life such as school, workplace, relations, and at the time of recreation and sport. All like to develop some skills and enhance abilities and talents. When a challenge is faced, all attention is focused on it. When the opportunities to develop the skills and talents is given all would like to progress. In these circumstances, the result is a sense of satisfaction. In the other word, human needs to competence; need to competence means the ability of a person in doing duties and that person have how much ability to achieve the desired objectives (Mulder, 2007).

Relatedness (continuity): relatedness is a need to emotional bonding with others and this need also expresses the desire of being emotional and being involved in intimate relationships. The requirement to relatedness causes to leading to people who certainly care about the well-being of a person and eschewing of people who do not care about her welfare. Need to relatedness is defined as ensuring communication with others and need to make self-experience as an individual worthy of love and respect. In the other words, individual requires to have a relationship with others and be supported by them (Johnston, 2010). 


\section{MATERIALS AND METHODS}

The method of this paper is descriptive-analytical and data collection is done using questionnaire. For this purpose, 200 men and women who were an applicant of cosmetic surgery and had come to beauty clinic of Imam Khomeini hospital in Tehran and were chosen using availability sampling method. And also analyzing data is done using the SPSS19 software.

\section{RESULTS AND DISCUSSION}

In order to a comprehensive analysis of data, a statistical method of multiple regressions was used and data was investigated based on findings and hypotheses. First hypothesis: psychological and perfectionism needs predict the cosmetic surgery applicants' perception of body image. For determining the relationship between psychological and perfectionism needs and cosmetic surgery applicants' perception of body image, multivariate regression is used whose digest is reported in Table 1.

Table 1. Summary of multiple regression analysis

\begin{tabular}{l|l|l|l|l|} 
Model & $\mathrm{R}$ & $\mathrm{R}^{2}$ & Justified $\mathrm{R}^{2} \mathrm{R}^{2}$ & Standard error \\
\hline & 0.54 & 0.29 & 0.27 & 26.14 \\
\hline
\end{tabular}

Predictor variables: psychological and perfectionism needs Criterion variable: perception of body image. As can be seen in the table, the intensity of the relationship between psychological needs (autonomy, competence, and dependence) and perfectionism (positive and negative) and cosmetic surgery applicants' perception of the body was calculated. Its value obtained 0.54 and they explain 20\% of changes in cosmetic surgery applicants' perception of body image.

As it is shown in Table 2, in the regression model, psychological needs (autonomy, competence, and dependence) and perfection (positive and negative) has a significant relationship $(\mathrm{F}=14.51, \mathrm{P}<0.01)$ with cosmetic surgery applicants' perception of body.The criterion variable: perception of body image.Results of the Table 3 indicate the share of each variable in the prediction of perception of body image model. As it is observable, positive and negative perfectionism factors have a significant share in the prediction of "body image perception" and the largest coefficients of beta equal to -0.37 belongs to negative perfectionism. In the other words, "negative perfectionism" factor has a stronger role in the prediction of "body image perception" in cosmetic surgery applicants.

Second hypothesis: psychological needs, perfectionism, and perception of body image of women and men who are an applicant of cosmetic surgery are different. At first, the assumption of equality of variances for psychological needs, perfectionism, and perception of body image was examined. As it is shown in Table 4, there is an equal assumption for psychological needs, perfectionism, and perception of the body of men and women applicants of cosmetic surgery.

After determining variances equality assumption, for comparing scores of psychological needs, perfectionism, and perception of body image of women samples, student's t-test was used for groups apart which results are reported in the table. According to Table 5, because significance level of " $\mathrm{t}$ " value (which is calculated by comparing psychological needs, perfectionism, and perception of image body of samples) is more than 0.05 , the fourth hypothesis was not confirmed. Therefore, it can

\begin{tabular}{|l|c|c|c|c|c|}
\hline \multicolumn{6}{|l|}{ Table 2. Summary results of analysis of variance for significance of regression model } \\
\hline Source of changes & Sum of squares & Degrees of freedom & Mean square & F & Significance level \\
\hline Regression & 49602.9 & 5 & 9920.58 & 14.51 & 0.001 \\
\hline remaining & 116898.72 & 171 & 683.61 & & \\
\hline Total & 166501.62 & 176 & & & \\
\hline
\end{tabular}

\begin{tabular}{|l|c|c|c|c|c|}
\hline \multicolumn{6}{|c|}{ Table 3. Summary of regression coefficients for psychological and perfectionism needs } \\
\hline Final model & $\begin{array}{c}\text { Regression } \\
\text { coefficient (B) }\end{array}$ & $\begin{array}{c}\text { Standard } \\
\text { error }\end{array}$ & $\begin{array}{c}\text { Standard } \\
\text { coefficient (Beta) }\end{array}$ & $\mathrm{t}$ & $\begin{array}{c}\text { Significance } \\
\text { level }\end{array}$ \\
\hline Autonomy & 0.13 & 0.36 & 0.03 & 1.35 & 0.72 \\
\hline Competence & 0.48 & 0.40 & 0.10 & 1.20 & 0.23 \\
\hline Dependence & 0.56 & 0.31 & 0.13 & 1.81 & 0.07 \\
\hline $\begin{array}{l}\text { Positive } \\
\text { perfectionism }\end{array}$ & 1.21 & 0.36 & 0.24 & 3.34 & 0.001 \\
\hline $\begin{array}{l}\text { Negative } \\
\text { perfectionism }\end{array}$ & -0.68 & 0.13 & -0.37 & -5 & 0.001 \\
\hline
\end{tabular}


Table 4. Summary of results Levene test for equality of variances

\begin{tabular}{|l|l|c|c|}
\hline \multirow{2}{*}{ Variables } & F & $\begin{array}{c}\text { Significance } \\
\text { level }\end{array}$ \\
\hline \multirow{3}{*}{$\begin{array}{l}\text { Psychological } \\
\text { needs }\end{array}$} & Autonomy & 0.16 & 0.68 \\
\cline { 2 - 4 } & Competence & 0.33 & 0.56 \\
\cline { 2 - 4 } & Dependence & 0.03 & 0.86 \\
\hline \multirow{4}{*}{ Perfectionism } & Positive & 0.58 & 0.29 \\
\cline { 2 - 4 } & Negative & 0.17 & 1.85 \\
\cline { 2 - 4 } & $\begin{array}{l}\text { Perception of } \\
\text { body image }\end{array}$ & 0.74 & 0.10 \\
\hline
\end{tabular}

be said that there is no significance relationship between men's and women's (applicants of cosmetic surgery) psychological needs, perfectionism, and perception of body.

\section{DISCUSSION}

According to the findings of this research, the first hypothesis was confirmed, and it was concluded that there is a significant relationship between psychological needs, perfectionism, and perception of body image of cosmetic surgery applicants. In addition, from predictive variables, "negative perfectionism" factor has a more effective role in the prediction of perception of body image in cosmetic surgery applicants. This result corresponded with findings of Hass, and Von Soest (2009) (Haas, 2008; Von Soest, 2009). Results of these studies have shown that there is a relationship among cosmetic surgery applicants' psychological needs, perfectionism, and perception of body image. The same as this research that has shown that negative perfectionism feature has more share in the prediction of body image in cosmetic surgery applicants. Since perfectionism increases the anxiety level and negative perfectionism leads people to the inefficient and non-constructive behaviors, so it further strengthens the basic needs of the motivational and psychological tendency of people. In people who do not have a favorable understanding of their own appearance, choosing cosmetic surgery without a justifiable medical reason is a solution based on emotional copying style (Nerini, 2014). It seems that the main motivational factor for this action is a failure to satisfy basic psychological needs. Awareness of this discontent is possible with a focus on "self". Intellectual challenges such as how people think about us and our belief about how they will behave have important implications on how we think about ourselves. When a person expects to be rejected for the sake of some of her features, she can choose between several different possible answers that choosing cosmetic surgery is one of these responses. Also in the second hypothesis, it was concluded that there are differences between men's and women's (cosmetic surgery applicants) psychological needs, perfectionism, and perception of body.

On the basis of findings of this research, the fourth hypothesis was not confirmed and it was concluded that there is no significant difference among psychological needs, perfectionism and perception of the body of samples. This result corresponds with study results of Pasha, Naderi and Akbari (2009) and sarwer (2005) (Naderi, 2008; Sarwer, 2005). Basic psychological requirements and perfectionism characteristic of people, over time and in the process of mental transformation, leading to the formation and evolution of the cognitive, emotional and behavioral characteristics. Accordingly, these factors will create inefficient perceptions of people toward themselves and their environment and will have concerns and conflicts about their appearance in the future. Therefore, men and women who were applicants of cosmetic surgery, in most cases did it influenced by the same motivational factors (Webb, 2015).

\section{REFERENCES}

Azin, A., Zhou, C., Jackson, T., Cassin, S., Sockalingam, S. and Hawa, R., 2014. Body contouring surgery after bariatric surgery: a study of cost as a barrier and impact on psychological well-being. Plastic and reconstructive surgery, 133(6), pp.776e-782e.

Balali E., Afshar Kohan J. 2010. Beauty and Money, Makeup and Surgery, Women Strategic Studies. pp. 47: 99-140.

Banfield, S.S. and McCabe, M.P., 2002. An evaluation of the construct of body image. Adolescence, 37(146), p.373.

Besharat M. A., 2007 Scale Construction and Validation of Multidimensional Perfectionism in Tehran. Psychological Reports, , 2(10), pp. 49-67.

Borzekowski, D.L. and Bayer, A.M., 2005. Body image and media use among adolescents. Adolescent medicine clinics, 16(2), p.289.

Cash, T.F., Phillips, K.A., Santos, M.T. and Hrabosky, J.I., 2004. Measuring "negative body image": validation of the Body Image Disturbance Questionnaire in a nonclinical population. Body image, 1(4), pp.363-372.

Garrusi, B., Garousi, S. and Baneshi, M.R., 2013. Body image and body change: predictive factors in an Iranian population. International journal of preventive medicine, 4(8).

Haas, C.F., 2008. Motivating factors for seeking cosmetic surgery: a synthesis of the literature. Plastic Surgical Nursing, 28(4), pp.177-182.

Hargreaves, D.A. and Tiggemann, M., 2006. 'Body Image is for Girls' A Qualitative Study of Boys' Body Image. Journal of Health Psychology, 11(4), pp.567-576.

Heyes, C.J., 2016. Cosmetic surgery: A feminist primer. Routledge. 
Hilhorst, M.T., 2002. Philosophical pitfalls in cosmetic surgery: a case of rhinoplasty during adolescence. Medical humanities, 28(2), pp.61-65.

Hwang, Peter H. (2004) Surgical rhinology: recent advances and future directions." Otolaryngologic Clinics of North America 37, no. 2: 489-499.

Johnston, M.M. and Finney, S.J., 2010. Measuring basic needs satisfaction: Evaluating previous research and conducting new psychometric evaluations of the Basic Needs Satisfaction in General Scale. Contemporary Educational Psychology, 35(4), pp.280-296.

McGee, B.J., Hewitt, P.L., Sherry, S.B., Parkin, M. and Flett, G.L., 2005. Perfectionistic self-presentation, body image, and eating disorder symptoms. Body image, 2(1), pp.29-40.

Mulder, R. and Bayer, J., 2007. Trainers' attitudes towards lifelong learning in relation to their competencies and their needs for professional training. In Unpublished paper delivered at the International Conference on HRD Practice and Research across Europe, Oxford. June (pp. 27-29).

Naderi F., Akbari S., Pasha G. 2008 Comparison of body image, body mass index, general health and self-concept among people who had cosmetic surgery, applicants of cosmetic surgery and ordinary people in Behbahan city. New findings in psychology. 2(7): 61-80

Nerini, A., Matera, C. and Stefanile, C., 2014. Psychosocial predictors in consideration of cosmetic surgery among women. Aesthetic plastic surgery, 38(2), pp.461-466.

Pearl, A. and Weston, J., 2003. Attitudes of adolescents about cosmetic surgery. Annals of plastic surgery, 50(6), pp.628-630.

Pesa, J.A., Syre, T.R. and Jones, E., 2000. Psychosocial differences associated with body weight among female adolescents: the importance of body image. Journal of Adolescent Health, 26(5), pp.330-337.

Rumsey, N. and Harcourt, D., 2004. Body image and disfigurement: issues and interventions. Body image, 1(1), pp.83-97.
Ryan, R.M. and Deci, E.L., 2000. Intrinsic and extrinsic motivations: Classic definitions and new directions. Contemporary educational psychology, 25(1), pp.54-67.

Sarwer, D.B., Cash, T.F., Magee, L., Williams, E.F., Thompson, J.K., Roehrig, M., Tantleff-Dunn, S., Agliata, A.K., Wilfley, D.E., Amidon, A.D. and Anderson, D.A., 2005. Female college students and cosmetic surgery: An investigation of experiences, attitudes, and body image. Plastic and reconstructive surgery, 115(3), pp.931-938.

Sarwer, D.B., Crerand, C.E. and Didie, E.R., 2003. Body dysmorphic disorder in cosmetic surgery patients. Facial plastic surgery, 19(01), pp.007-018.

Sheldon, K.M., Elliot, A.J., Kim, Y. and Kasser, T., 2001. What is satisfying about satisfying events? Testing 10 candidate psychological needs. Journal of personality and social psychology, 80(2), p.325.

Slade, P.D. and Owens, R.G., 1998. A dual process model of perfectionism based on reinforcement theory. Behavior modification, 22(3), pp.372-390.

Stoeber, J., Harris, R.A. and Moon, P.S., 2007. Perfectionism and the experience of pride, shame, and guilt: Comparing healthy perfectionists, unhealthy perfectionists, and non-perfectionists. Personality and Individual Differences, 43(1), pp.131-141.

Tavassoli G., Modiri F., 2012. Women's Tendency toward Cosmetic Surgery in Tehran, Women's Studies, 10(1), pp 61-80

Von Soest, T., Kvalem, I.L., Roald, H.E. and Skolleborg, K.C., 2009. The effects of cosmetic surgery on body image, selfesteem, and psychological problems. Journal of plastic, reconstructive \&t Aesthetic Surgery, 62(10), pp.1238-1244.

Webb, J.B., Wood-Barcalow, N.L. and Tylka, T.L., 2015. Assessing positive body image: Contemporary approaches and future directions. Body image, 14, pp.130-145.

Weiss, G., 2013. Body images: Embodiment as inter corpo reality. Routledge

Wolf, N., 2013. The beauty myth: How images of beauty are used against women. Random House. 